\title{
Erratum to: In vitro and in vivo pharmacokinetics and metabolism of synthetic cannabinoids CUMYL-PICA and 5F-CUMYL-PICA
}

\author{
Richard C. Kevin ${ }^{1,2} \cdot$ Timothy W. Lefever ${ }^{3}$ Rodney W. Snyder ${ }^{3}$. \\ Purvi R. Patel ${ }^{3}$ - Timothy R. Fennell ${ }^{3}$ - Jenny L. Wiley ${ }^{3}$ - Iain S. McGregor ${ }^{1,2}$. \\ Brian F. Thomas ${ }^{3}$
}

Published online: 1 August 2017

(c) Japanese Association of Forensic Toxicology and Springer Japan KK 2017

\section{Erratum to: Forensic Toxicol (2017) 35:333-347 DOI 10.1007/s11419-017-0361-1}

The article, In vitro and in vivo pharmacokinetics and metabolism of synthetic cannabinoids CUMYL-PICA and 5F-CUMYL-PICA, written by Richard C. Kevin, Timothy W. Lefever, Rodney W. Snyder, Purvi R. Patel, Timothy R. Fennell, Jenny L. Wiley, Iain S. McGregor and Brian F. Thomas, was originally published Online First without open access. After publication in volume 35, issue 2, page 333-347, the author decided to opt for Open Choice and to make the article an open access publication. Therefore, the copyright of the article has been changed to (c) The Author(s) 2017 and the article is forthwith distributed under the terms of the Creative Commons Attribution 4.0 International License (http://creativecommons.org/licen ses/by/4.0/), which permits use, duplication, adaptation, distribution and reproduction in any medium or format, as long as you give appropriate credit to the original author(s) and the source, provide a link to the Creative Commons license, and indicate if changes were made.
The online version of the original article can be found under doi:10.1007/s11419-017-0361-1.

Richard C. Kevin

richard.kevin@sydney.edu.au

1 School of Psychology, The University of Sydney, A18, Sydney, NSW 2006, Australia

2 The Lambert Initiative for Cannabinoid Therapeutics, The University of Sydney, Sydney, NSW 2050, Australia

3 RTI International, 3040 Cornwallis Road, Research Triangle Park, Durham, NC 27709, USA 